\title{
The infection rate in new diagnosis and relapsed/refractory multiple myeloma patients who had bortezomib-based chemotherapy and relationship between development of infection and lymphocyte/monocyte ratio
}

\author{
Merve Pamukçuoğlu${ }^{1}$, Nuran Ahu Baysal ${ }^{2} \oplus$, Mehmet Sezgin Pepeler ${ }^{1 \oplus}$
}

${ }^{1}$ Department of Hematology and Bone Marrow Transplantation, Ankara City Training and Research Hospital, Ankara, Turkey ${ }^{2}$ Department of Hematology, University of Health Sciences, Ankara Dr. Abdurrahman Yurtaslan Oncology Training and Research Hospital, Ankara, Turkey

\begin{abstract}
Objectives: Multiple Myeloma (MM) is a disease caused by the clonal proliferation of plasma cells. In recent years, proteozom inhibitors, immunomodulatory agents and monoclonal antibodies have been used in the treatment of MM. In this study, the relation of bortezomib, one of the proteozoma inhibitors used in the treatment of MM, with the development of infection was investigated.

Methods: We retrospectively evaluated 56 patients who had MM treated with bortezomib-based regimen. We tried to determine the relationship between infection with immunoglobulin $\mathrm{G}$ levels at the time of diagnosis, lymphocyte absolute values at the time of diagnosis, lymphocyte absolute values at the time of chemotherapy, neutrophil absolute value at the time of chemotherapy, lymphocyte absolute values at the time of infection, monocyte absolute value at the time of infection, and the lymphocyte/monocyte (L/M) ratio at the time of infection. The effects of L/M ratio on progression free survival (PFS) and overall survival (OS) were also examined.
\end{abstract}

Results: Thirty (53.6\%) of the 56 patients were newly diagnosed, $26(46.4 \%)$ of 56 patients were relapsed/refractory MM. The bortezomib-based regimen was given to all patients. Of the 56 patients included in the study, $21(37.5 \%)$ were female, 35 were male (62.5\%). The ages of the patients was 28-79 years (median: 58.5 years). No infection attack was observed in $31(55.4 \%)$ patients. Disease stage (R-ISS) $(p=0.032)$, presence or absence of co-morbid disease $(p=0.035)$, disease status during an infection attack $(p<0.01)$, lymphocytopenia at the time of chemotherapy $(p=0.003)$, absolute value of lymphocytopenia at the time of infection attack $(p<0.01)$ and $\mathrm{L} / \mathrm{M}$ ratio $(p<0.01)$ had a significant relation with development of infection. Lymphocytopenia at the time of infection attack $(p<0.01, \mathrm{OR}<1,94.6 \% \mathrm{CI})$ and L/M ratio $(p<0.01, \mathrm{OR}<$ $1,91.1 \% \mathrm{CI}$ ) had been found significant in univariate logistic regression analysis. Lymphocytopenia at the time of infection attack $(p=0.002, \mathrm{OR}<1,95 \% \mathrm{CI})$ and $\mathrm{L} / \mathrm{M}$ ratio $(p=0.003, \mathrm{OR}<1,95 \% \mathrm{CI})$ had been found significant in multivariate logistic regression analysis. L/M ratio had a significant effect on OS $(p<$ $0.017)$ but not on PFS $(p>0.05)$.

Conclusions: It was determined that $\mathrm{L} / \mathrm{M}$ ratio has an effect on OS and it is also an independent factor on the development of infection. OS was decreasing and the risk of developing infection was increasing, when the $\mathrm{L} / \mathrm{M}$ ratio was low.

Keywords: bortezomib, infection, lymphocyte/monocyte ratio

How to cite this article: Pamukçuoğlu M, Baysal NA, Pepeler MS. The infection rate in new diagnosis and relapsed/refractory multiple myeloma patients who had bortezomib-based chemotherapy and relationship between development of infection and lymphocyte/monocyte ratio . Eur Res J 2021;7(6):541549. DOI: $10.18621 /$ eurj. 855510

Address for correspondence: Merve Pamukçuoğlu, MD., Ankara City Training and Research Hospital, Department of Hematology and Bone Marrow Transplantation,Bilkent, Ankara,Turkey.E-mail:drmpamuk@yahoo.com,Tel: +90 5052458374 
$\mathbf{M}$ uliple Myeloma (MM) is a disease caused by clonal proliferation of plasma cells. It constitutes $10 \%$ of hematological cancers. For diagnosis, $\geq$ $10 \%$ clonal bone marrow plasma cells in bone marrow or a biopsy proven plasmacytoma plus evidence of one or more multiple myeloma defining events (MDE) namely CRAB (hypercalcemia, renal failure, anemia, or lytic bone lesions). Plasma cell disorder defined as bone marrow clonal plasmacytosis $\geq 60 \%$, serum involved/uninvolved free light chain (FLC) ratio $\geq 100$ (provided involved FLC is $\geq 100 \mathrm{mg} / \mathrm{L}$ ), or $>1$ focal lesion on magnetic resonance imaging (MRI) [1].

Many chemotherapeutic agents are used in the treatment of MM. The use of melphalan in the treatment of MM was a revolution in the 1950s [2], and then the demonstration of the effect of high-dose melphalan and autologous stem cell transplantation on progression-free survival changed the standard treatment approaches in MM [3] In the last 10 years, immunomodulatory drugs such as Thalidomide, Lenalidomide, Pomalidomid (IMID) and proteasome inhibitors such as Bortezomib have been started to use $[4,5]$. Subsequently, CD38-targeted monoclonal antibody 'Daratumumab' was added in the MM patients' treatment [6]. Bortezomib is still being the first treatment option in MM in Turkey.

With the use of high-dose melphalan and bortezomib and new agents in the IMID group, there was a dramatic change in the mean survival in MM patients. Overall survival had been extended from 3 years to 810 years. This increase in efficacy also led to changes in the spectrum of side effects. Humoral immunodeficiency has been usually seen in MM patients. After using these drugs in the MM patients' treatment, they began to affect cellular immune functions, and changing infectious complication processes were begun $[7$, 8].

Bortezomib is a molecule that reversibly and selectively inhibits the $26 \mathrm{~S}$ proteasome and shows its effect through nuclear factor-kB (NF-kB) [7, 9-11]. It causes apoptosis by inhibition of NF-kB. It also performs $\mathrm{T}$ cell suppression through the same mechanism. Therefore, $\mathrm{T}$ cells containing high levels of NF-kB are more sensitive to bortezomib treatment. $\mathrm{CD}^{+} \mathrm{T}$ cells affected by bortezomib treatment produce less IFN-gamma and IL-2 [10]. This explains the anti-inflammatory and immunomodulatory effect of bortezomib [7].
Hematological side effects occur due to the anti-inflammatory and immunomodulating effects of bortezomib. The most important of these are neutropenia and thrombocytopenia [7]. Monocytopenia and lymphocytopenia (T-cell suppression) associated with bortezomib treatment may also occur $[8,9]$.

In this study, it is aimed to reveal the relationship between infection development with variables such as absolute lymphocyte value, lymphocyte/monocyte ratio $(\mathrm{L} / \mathrm{M})$, and IgG level in newly diagnosed and relapsed/refractor MM patients who had treated with bortezomib-based chemotherapy. At the same time, the $\mathrm{L} / \mathrm{M}$ ratio and overall survival relationship had been determined.

\section{METHODS}

We retrospectively evaluated 56 patients who had MM treated with bortezomib based regimen. Type of Infection were determined. Lymphocyte absolute values at the time of diagnosis, immunoglobulin $G$ levels at the time of diagnosis, lymphocyte absolute values at the time of chemotherapy, neutrophil value at the time of chemotherapy, lymphocyte absolute values at the time of infection, and monocyte absolute value at the time of infection were recorded from the file information. The $\mathrm{L} / \mathrm{M}$ ratio of the patients at the time of infection were calculated and transferred to the SPSS database. We tried to determine the relationship between infection with immunoglobulin $G$ levels at the time of diagnosis, lymphocyte absolute values at the time of diagnosis, lymphocyte absolute values at the time of chemotherapy, lymphocyte absolute values at the time of infection, monocyte absolute value at the time of infection, and the L/M ratio at the time of infection. The effects of $\mathrm{L} / \mathrm{M}$ ratio on progression free survival (PFS) and overall survival (OS) were also examined.

Gazi University Faculty of Medicine ethical committee has approved this study on 12/09/2014 with the number of 25901600-3086.

\section{Determinations}

International staging system (ISS):

- Stage-I: serum beta - 2 microglobulin level $<3.5$ $\mathrm{mg} / \mathrm{dl}$ and serum albumin level $\geq 3.5 \mathrm{~g} / \mathrm{dl}$

- Stage-II: out of ISS stage I and stage III criteria 
- Stage-III: serum beta-2 microglobulin level $\geq 5.5$ $\mathrm{mg} / \mathrm{L}[12]$.

\section{Revised International Staging System (R-ISS):}

- R-ISS I: serum $\beta 2$-microglobulin level $<3.5$ $\mathrm{mg} / \mathrm{L}$, serum albumin level $\geq 3.5 \mathrm{~g} / \mathrm{dL}$, no high-risk cytogenetic anomaly (CA) $[\operatorname{del}(17 \mathrm{p})$ and/or $\mathrm{t}(4 ; 14)$ and/or $\mathrm{t}(14 ; 16)]$, and normal LDH level (less than the upper limit of normal range)

- R-ISS II : out of ISS stage I and stage III criteria

- R-ISS III: serum $\beta 2$-microglobulin level > 5.5 $\mathrm{mg} / \mathrm{L}$ and high-risk CA or high LDH level [13].

Table 1. Patients' MM subtypes, M protein level, ISS and R-ISS stages and Comorbidity at the diagnosis

\begin{tabular}{|c|c|c|}
\hline & Number of the patients & $\%$ \\
\hline \multicolumn{3}{|l|}{ MM subtypes } \\
\hline IgG kappa & 24 & 42.9 \\
\hline IgG lambda & 13 & 23.2 \\
\hline Ig A kappa & 3 & 5.4 \\
\hline Ig A lambda & 4 & 7.1 \\
\hline Ig D lambda & 3 & 5.4 \\
\hline kappa light chain & 4 & 7.1 \\
\hline lambda light chain & 4 & 7.1 \\
\hline non-secretory & 1 & 1.8 \\
\hline \multicolumn{3}{|l|}{ M protein level } \\
\hline$<3 \mathrm{~g} / \mathrm{dl}$ & 13 & 23.2 \\
\hline$>3 \mathrm{~g} / \mathrm{dl}$ & 43 & 76.8 \\
\hline \multicolumn{3}{|l|}{ ISS stage } \\
\hline stage-1 & & 21.4 \\
\hline stage-2 & 10 & 17.9 \\
\hline stage-3 & 34 & 60.7 \\
\hline \multicolumn{3}{|l|}{ R-ISS stage } \\
\hline stage-1 & 10 & 17.9 \\
\hline stage-2 & 29 & 51.8 \\
\hline stage-3 & 17 & 30.4 \\
\hline \multicolumn{3}{|l|}{ Co-morbidity } \\
\hline no co-morbidity & 22 & 39.3 \\
\hline DM & 9 & 16.1 \\
\hline $\mathrm{CRF}$ & 10 & 17.9 \\
\hline HT & 9 & 16.1 \\
\hline AHD & 3 & 5.4 \\
\hline COPD & 1 & 1.8 \\
\hline $\mathrm{HF}$ & 1 & 1.8 \\
\hline $\mathrm{ARF}+\mathrm{SM}+\mathrm{COPD}+\mathrm{HT}$ & 1 & 1.8 \\
\hline
\end{tabular}




\section{Statistical Analysis}

Descriptive statistics were presented as mean \pm standard deviation and median (minimum-maximum) for numerical variables, and as percentages for categorical variables. The normal distribution of parametric values was determined by the Shapiro-Wilk Test. For determining the significance In statistical analysis, the T-test was used for parametric variables, Mann Whitney U test was used for non-parametric variables. Pearson Chi-Square Test was used to comparing two categorical variables. Univariate and multivariate logistic regression analyzes were performed for advanced statistical analysis. Log-Rank test was used to calculate survival analysis. All statistical evaluations were made using the Statistical Package for Social Sciences (SPSS) for Windows 16 (IBM SPSS Inc., Chicago, IL) program. Statistical significance p-value was accepted as $<0.05$ in all analyzes.

\section{RESULTS}

Of the 56 patients included in the study, 21 $(37.5 \%)$ were females and $35(62.5 \%)$ were males. The median age of the patients was 58.5 years (minmax: $28-79$ years). Thirty (53.6\%) of 56 patients were newly diagnosed, $26(46.4 \%)$ of 56 patients were relapsed/refractor MM. Table 1 show the patients' MM subtypes, M protein level, ISS and R-ISS stages and co-morbidity at the time of diagnosis. The bortezomibbased regimen was given to all patients. Accordingly, $43(76.8 \%)$ patients had bortezomib $1.3 \mathrm{mg} / \mathrm{m} 2 \mathrm{sc}(1$, 8,15 , and 22 days), cyclophosphamide $300 \mathrm{mg} / \mathrm{m} 2$ PO $(1,8,15$, and 22 days) and dexamethasone $40 \mathrm{mg}$ (1, 8,15 , and 22 days) (VCD) regimen, 13 patients
(23.2\%) had bortezomib $1.3 \mathrm{mg} / \mathrm{m}^{2} \mathrm{sc}$ (Days 1, 8, 15, and 22), melphalan $9 \mathrm{mg} / \mathrm{m} 2 \mathrm{PO},(1-4$ Days) and prednisone $60 \mathrm{mg} / \mathrm{m}^{2} \mathrm{PO}$, (Days 1-4) (VMP) chemotherapy regimen.

Thirty-one (55.4\%) patient did not have any infection. Pulmonary infection was seen in $17(30.4 \%)$ patients, urinary system infection was seen in 3 (5.4\%) patients, lung and urinary system infection was seen in $2(3.6 \%)$ patients, cellulitis was seen in $1(1.8 \%)$ patient, psoas abscess was seen in $1(1.8 \%)$ patient, the unknown origin of fever was seen in $1(1.8 \%)$ patient. Twelve $(21.4 \%)$ of the patients had an infection in the first cycle, others had an infection in the second or more cycles. Infection agents could be isolated in only 7 (12.5\%) patients. Accordingly: E. Coli infection was seen in $5(8.9 \%)$ patients, viral infection was seen in 1 (1.8\%) patient, and coagulase-negative staphylococcal infection was seen in $1(1.8 \%)$ patient. While the patients received bortezomib-based chemotherapy, the median neutrophil values was $0 / \mathrm{mcL}$ (min-max: 0 $4000 / \mathrm{mcL})$. In 8 (14.3\%) patients; neutrophil level was $\leq 1000 / \mathrm{mcL}$, and in $48(85.7 \%)$ patients; neutrophil level was $>1000 / \mathrm{mcL}$. Before starting chemotherapy, median basal lymphocyte absolute values was 14051/ mcL (min-max: 320-3190/mcL). The median lymphocyte values measured while receiving chemotherapy was 636/mcL (min-max: 32-1890 mcL ). The median lymphocyte absolute values of the patients in the infection attack was $1775 / \mathrm{mcL}$ (min-max: $30-4000 / \mathrm{mcL})$. In twenty (35.7\%) patients; lymphocyte values was $\leq 1000 / \mathrm{mcL}$, in 36 patients $(64.3 \%)$ lymphocyte values was $>1000 / \mathrm{mcL}$. The median monocyte absolute values of the patients in the infection attack was 434/mcL (min-max: 80-1000/mcL). The median $\mathrm{IgG}$ value at diagnosis was $3000 \mathrm{mg} / \mathrm{dl}$

Table 2. Value of age, median level of $\mathrm{Ig} G$ level at diagnosis, lymphocytopenia at the time of chemotherapy and $L / M$ ratio

\begin{tabular}{lccc}
\hline & Infection negative & Infection positive & $\boldsymbol{p}$ value \\
\hline Age & $55.87 \pm 11.0$ & $61.6 \pm 112.2$ & $0.07 \mathrm{t}$ \\
Ig G level at diagnosis & $3325(305-10800)$ & $3000(141-13800)$ & $0.93 \mathrm{MU}$ \\
$\begin{array}{l}\text { Lymphocytopenia at the } \\
\text { time of chemotherapy }\end{array}$ & $780(50-1890)$ & $300(32-1780)$ & $0.003 \mathrm{MU}$ \\
L/M ratio & $4.6(1.5-45)$ & $0.88(0.04-5)$ & $0.00 \mathrm{MU}$ \\
\hline
\end{tabular}

Data are shown as mean \pm standard deviation or median (min-max). L/M = lymphocyte/monosyte

T-test, MU: Mann Whitney U test 
Table 3. Variables that are found to be statistically significant/not statistically significant

\begin{tabular}{|c|c|c|c|}
\hline & Infection negative & Infection positive & $p$ value \\
\hline \multicolumn{4}{|l|}{ Gender, n (\%) } \\
\hline Female & $12(38.7)$ & $9(36)$ & $0.83 \times 2$ \\
\hline Male & $19(61.3)$ & $16(64)$ & \\
\hline Total & $31(100)$ & $25(100)$ & \\
\hline \multicolumn{4}{|c|}{ Subtypes of MM, n (\%) } \\
\hline Ig G kappa & $15(48.4)$ & $9(36)$ & $0.35 \times 2$ \\
\hline Others & $16(51.6)$ & $16(64)$ & \\
\hline Total & $31(100)$ & $25(100)$ & \\
\hline \multicolumn{4}{|l|}{ ISS, n (\%) } \\
\hline Stage-I & $8(25.8)$ & $4(16)$ & $0.29 \times 2$ \\
\hline Stage -II & $7(22.6)$ & $3(12)$ & \\
\hline Stage -III & $16(51.6)$ & $18(72)$ & \\
\hline Total & $31(100)$ & $25(100)$ & \\
\hline \multicolumn{4}{|l|}{ R-ISS, n (\%) } \\
\hline Stage $-\mathrm{I}$ & $6(19.4)$ & $4(16)$ & $0.032 \times 2$ \\
\hline Stage-II & $20(64.5)$ & $9(36)$ & \\
\hline Stage-III & $5(16.1)$ & $12(48)$ & \\
\hline Total & $31(100)$ & $25(100)$ & \\
\hline \multicolumn{4}{|l|}{ Co-morbidity, n (\%) } \\
\hline No & $16(51.6)$ & $6(24)$ & $0.035 \times 2$ \\
\hline Yes & $15(48.4)$ & $19(76)$ & \\
\hline Total & $31(100)$ & $25(100)$ & \\
\hline \multicolumn{4}{|l|}{ Diesea state, n (\%) } \\
\hline $\mathrm{CR}$ & $31(100)$ & $1(4)$ & $<0.01 \times 2$ \\
\hline Others & 0 & $24(96)$ & \\
\hline Total & $31(100)$ & $25(100)$ & \\
\hline \multicolumn{4}{|c|}{ Levelof M protein, n (\%) } \\
\hline$<3 \mathrm{gr} / \mathrm{dl}$ & $9(29)$ & $4(16)$ & $0.25 \times 2$ \\
\hline$>3 \mathrm{gr} / \mathrm{dl}$ & $22(71)$ & $21(84)$ & \\
\hline Total & $31(100)$ & $25(100)$ & \\
\hline \multicolumn{4}{|l|}{ Level of creatinin } \\
\hline$<2 \mathrm{mg} / \mathrm{dl}$ & $22(71)$ & $14(56)$ & $0.24 \times 2$ \\
\hline$>2 \mathrm{mg} / \mathrm{dl}$ & $9(29)$ & $11(44)$ & \\
\hline Total & $31(100)$ & $25(100)$ & \\
\hline \multicolumn{4}{|l|}{ Typeofchemotherapy } \\
\hline VCD & $25(80.6)$ & $18(72)$ & $0.44 \times 2$ \\
\hline VMP & $6(19.4)$ & $7(28)$ & \\
\hline Total & $31(100)$ & $25(100)$ & \\
\hline \multicolumn{4}{|c|}{ Number of Bortezomib cycles } \\
\hline$\leq 4$ cycle & $27(87.1)$ & $21(88)$ & $0.53 \times 2$ \\
\hline$>4$ cycle & $4(12.9)$ & $4(12)$ & \\
\hline Total & $31(100)$ & $25(100)$ & \\
\hline \multicolumn{4}{|l|}{ Neutropenia } \\
\hline$<1000$ & $2(6.5)$ & $6(24)$ & $0.06 \times 2$ \\
\hline$>1000$ & $29(93.5)$ & $19(76)$ & \\
\hline Total & $31(100)$ & $25(100)$ & \\
\hline \multicolumn{4}{|l|}{ Lymphocytopenia } \\
\hline$<1000$ & 0 & $20(80)$ & $<0.01 \times 2$ \\
\hline$>1000$ & $31(100)$ & $5(20)$ & \\
\hline Total & $31(100)$ & $25(100)$ & \\
\hline
\end{tabular}

$\mathrm{L} / \mathrm{M}=$ lymphocyte/monosyte, ISS = international scoring system, R-ISS = revised- international scoring system, VCD

= bortezomib, cyclophosphamide, dexamethasone, $\mathrm{VMP}=$ bortezomib, melphalan, prednisolone, $\mathrm{x} 2$ : chi-quare test 
Table 4. Univariate and multivariate analysis of variables

\begin{tabular}{lcccccc}
\hline & \multicolumn{3}{c}{ UNIVARIATE ANALYSIS } & \multicolumn{3}{c}{ MULTIVARIATE ANALYSIS } \\
\hline & OR & $95 \%$ CI & $p$ value & OR & $95 \%$ CI & $p$ value \\
Co-morbidity & 3.37 & $1.06-10.7$ & 0.039 & 0.4 & $0.17-1.29$ & 0.146 \\
$\begin{array}{l}\text { Diseade State } \\
\text { Lymphocytopenia at the time } \\
\text { of chemotherapy }\end{array}$ & 0.99 & $0.99-1$ & $<0.01$ & 3.6 & $0-1$ & 0.95 \\
Lymphocytopenia & 0.99 & $0.99-1$ & 0.018 & 0.96 & $0.06-15$ & 0.99 \\
L/M ratio & 0.173 & $0.094-0.998$ & $<0.01$ & 0.99 & $0.99-1$ & 0.002 \\
\hline
\end{tabular}

$\mathrm{L} / \mathrm{M}=$ lymphocyte/monosyte, $\mathrm{CI}=$ confidental interval, $\mathrm{OR}=$ odss ratio

(min-max: 141-13800 mg/dl). The median value of L/M ratio was 2.00 (min-max: 0.04-45).

A statistically significant correlation was seen in disease stage (R-ISS) $(p=0.032)$, presence or absence of co-morbid disease $(p=0.035)$, disease status during an infectious attack $(p<0.01)$, lymphocytopenia at the time of chemotherapy ( $p=0.003)$, absolute value of lymphocytopenia at the time of infection $(p<0.01)$ and the $\mathrm{L} / \mathrm{M}$ ratio $(p<0.01)$ with the development of infection. According to the R-ISS, patients who had stage 3 and in the presence of co-morbid disease had a higher infection risk while the infection rates were low in patients who had a complete response. Lymphocytopenia was related to the development of infection. Especially, patients who had $\leq 1000 / \mathrm{mcL}$ ( $p<$ $0.01)$ lymphocyte level and who had a low L/M ratio $(<2)$ had a high risk of development of infection. Variables that are found to be statistically significant (or not statistically significant) relation with development of infection are shown in Table 2 and Table 3.

Disease status during infection $(p<0.01, \mathrm{OR}<1$, $98.2 \% \mathrm{CI})$, lymphocytopenia at the time of infection $(p<0.01, \mathrm{OR}<1,94.6 \% \mathrm{CI})$ and $\mathrm{L} / \mathrm{M}$ ratio $(p<0.01$, $\mathrm{OR}<1,91.1 \% \mathrm{CI})$ were significant in univariate logistic regression analysis. Infection rate was lower in

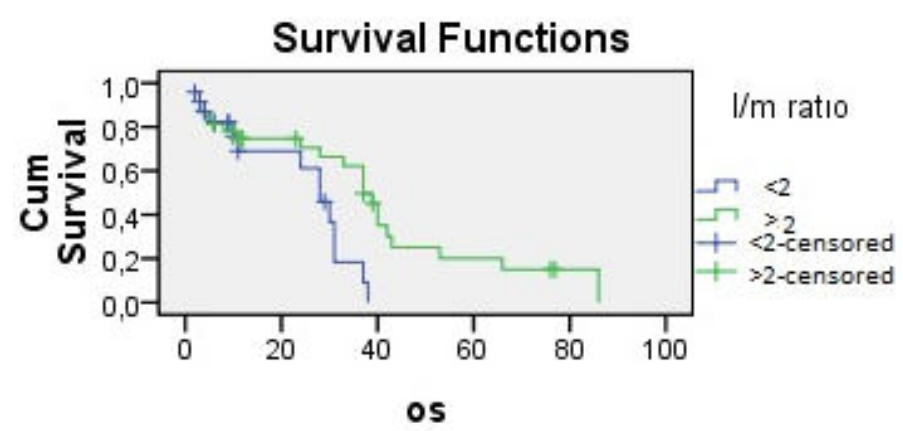

Fig. 1. Relationship between lymphocyte/monosyte (L/M) ratio and survival. patients with complete response. Accordingly, infection rates increase in patients who had lymphocytopenia and in patients who had a low level of $\mathrm{L} / \mathrm{M}$ ratio. Significant parameters in univariate analysis were reevaluated in multivariate logistic regression analysis, lymphocytopenia at the time of infection and $\mathrm{L} / \mathrm{M}$ ratio were found significant (respectively: $p=0.002$, OR $<1,95 \% \mathrm{CI} ; p=0.003, \mathrm{OR}<1,95 \% \mathrm{CI})$. The variables that are significant in univariate and multivariate analysis are shown in Table 4.

When the effects of the independent variable of $\mathrm{L} / \mathrm{M}$ ratio on $\mathrm{PFS}$ and $\mathrm{OS}$ were examined; $\mathrm{L} / \mathrm{M}$ ratio had no significant effect on PFS $(p>0.05)$, while had a significant effect on OS $(p<0.017)$. The mean OS was $33 \pm 2.7$ months (min-max: 27.53-38.47 months). The cut-off value of the $\mathrm{L} / \mathrm{M}$ ratio was 2 (this is the median value of the $\mathrm{L} / \mathrm{M}$ ratio). Mean OS survival of patients who had $\mathrm{L} / \mathrm{M} \geq 2$ was $37 \pm 2.5$ months (minmax: 32- 41.96 months), mean OS of patients who had $\mathrm{L} / \mathrm{M}<2$ was $28 \pm 3.2$ months (min-max: 21.7-34.27/ months). Fig. 1 show relationships between the OS and the $\mathrm{L} / \mathrm{M}$ ratio.

\section{DISCUSSION}

It has been reported in the literature that the frequency of viral infections is high in MM patient who had a bortezomib therapy. Especially, it has been emphasized that there is a relationship between bortezomib and Herpes Zoster infection [10, 11, 14]. As we have been stated, the relationship between bortezomib and infection development is due to the lymphocytopenia-inducing effect of bortezomib [6]. The result we obtained in this study also supports these findings. It has been shown that lymphocytopenia and the decrease in the L/M ratio are independent variables on 
the development of infection. We also find that R-ISS, co-morbidity, disease state have significant affect on development of infection in MM patients, however, were not found an independent factors.

Pang et al. [15] claimed that neutrophile+monocyte/lymphocyte ratio (NMLR) is an independent variable on progression-free survival. Newly diagnosed patients who received VCD chemotherapy regimen were included in this study. The NMLR ratio was calculated for each patient and a value of 1.9 was taken as the cut-off value. It has been shown that immune restructuring is more effective and disease exacerbation is less in patients who had a NMLR $<1.9$. On the other hand, it is known that the microenvironment is important in the course of the disease in MM patients. Neutrophils, lymphocytes and monocytes are being in this microenvironment $[16,17]$. In some studies, it has been shown that the ratio of absolute neutrophil value to absolute lymphocyte value and the ratio of absolute lymphocyte value to absolute monocyte value are effective in immune remodeling in MM patients, and this affects progression-free survival $[16,18,19]$. It is also emphasized that the cells that are particularly effective in the microenvironment of MM are neutrophils and monocytes, and the treatment options may change according to the neutrophil lymphocyte ratio and the lymphocyte-monocyte ratio in patients with MM [20]. In recent years, the use of immunomodulatory drugs and the use of CAR-T cell therapy, especially in patients with relapsed / refractory MM, have shown the importance of immune abnormality in the course of the disease in patients with MM. In vivo balance to be established in the immune environment affects the course of the disease [21].

It has been shown that absolute neutrophil value, absolute lymphocyte value, and absolute monocyte value and their ratio to each other are independent variables in solid tumors and hematological cancers and in the course of the disease after autologous stem cell transplantation [22-26]. In most of these studies, it was shown that high neutrophil/lymphocyte ratio and low lymphocyte/monocyte ratio were associated with poor prognosis. On the contrary, there are studies in the literature that showing the neutrophil/lymphocyte ratio is not effective on survival [19]. Romena et al. [20], showed that the monocyte ratio is effective on the microenvironment in myeloma bone marrow. Especially, it is emphasized that it enables growth in myeloma cells. When all these are taken into consideration, it is emphasized that neutrophil, lymphocyte and monocytes and especially NMLR parameter are effective on survival in MM patients. The reason for better progression-free survival in patients with a low NMLR rate may be due to the low monocyte ratio that enables the growth of the myeloma cell. There are also studies claiming that the increase in the $\mathrm{L} / \mathrm{M}$ ratio is associated with a good prognosis [26] It is still unknown how the changes in lymphocyte and monocyte ratio affect the risk of infection. However, absolute lymphocyte value, absolute monocyte value and $\mathrm{L} / \mathrm{M}$ ratio are closely related to the immune system [27]. It is also known that alloreactive $\mathrm{T}$ lymphocytes are suppressed, especially in bortezomib-based regimens [10]. As a result of all these, it can be said that absolute lymphocyte and monocyte values and $\mathrm{L} / \mathrm{M}$ ratio might be occurred predisposition for infections. It is also known that bortezomib prevents the growth of myeloma cells with causing to monocytopenia.

Decreasing in the $\mathrm{L} / \mathrm{M}$ ratio, in other words, higher monocyte value relative to lymphocyte value, might be associated with infection in bortezomibbased regimens. If bortezomib-based regimen is used in relapsed refractory cases or newly diagnosed cases of MM, lymphocytopenia should be tried to prevent. On the other hand, it is necessary to keep the monocyte value at certain rates in order to prevent tumor growth. Yang et al. [27], examined the relationship between $\mathrm{L} / \mathrm{M}$ ratio and $\mathrm{OS}$. The median $\mathrm{L} / \mathrm{M}$ ratio in our study is the 2 . Overall survival was longer in patients who had $\mathrm{L} / \mathrm{M}$ ratio $\geq 2$.

\section{CONCLUSION}

It was determined that $\mathrm{L} / \mathrm{M}$ ratio has an effect on OS and it is also an independent factor on the development of infection. OS was decreasing and the risk of developing infection was increasing, when the L/M ratio was low. We have to say that; there is some restriction in this study such as number of patients and power effect of lymphocytopenia in multivariate analysis. Therefore; more studies which are including more patients, are needed for claiming the lymphocytopenia and $\mathrm{L} / \mathrm{M}$ ratio are an independent variable on the development of infection and L/M ratio has an effect on OS. After then, L/M will be a follow-up pa- 
rameter in the development of infection in bortezomibbased regimens and it will be considered as an effective parameter on OS.

\section{Authors' Contribution}

Study Conception: MP, NAB, MSP; Study Design: MP, NAB, MSP; Supervision: MP, NAB, MSP; Funding: MP, NAB, MSP; Materials: MP, NAB, MSP; Data Collection and/or Processing: MP, NAB, MSP; Statistical Analysis and/or Data Interpretation: MP, NAB, MSP; Literature Review: MP, NAB, MSP; Manuscript Preparation: MP, NAB, MSP and Critical Review: MP, NAB, MSP.

\section{Conflict of interest}

The authors disclosed no conflict of interest during the preparation or publication of this manuscript.

\section{Financing}

The authors disclosed that they did not receive any grant during conduction or writing of this study.

\section{REFERENCES}

1. Rajkumar SV. Multiple myeloma: 2020 update on diagnosis, risk-stratification and management. Am J Hematol 2020;95:54867.

2. Bergsagel DE, Sprague CC, Austin C, Griffith KM. Evaluation of new chemotherapeutic agents in the treatment of multiple myeloma: IV. L-Phenylalanine mustard (NSC-8806). Cancer Chemother Rep 1962;21:87-99.

3. Attal M, Harousseau JL, Stoppa AM, Sotto JJ, Fuzibet JG, Rossi JF et al. A prospective, randomized trial of autologous bone marrow transplantation and chemotherapy in multiple myeloma. Intergroupe Français du Myélome. N Engl J Med 1996;335:917.

4. Morgan GJ1, Davies FE. Role of thalidomide in the treatment of patients with multiple myeloma. Crit Rev Oncol Hematol 2013;88 Suppl 1:S14-22.

5. Abe Y, Ishida T. Immunomodulatory drugs in the treatment of multiple myeloma. Jpn J Clin Oncol 2019;49:695-702.

6. Touzeau C, Moreau P. Daratumumab for the treatment of multiple myeloma. Expert Opin Biol Ther 2017;17:887-93.

7. Pamukçuoğlu M, Emmez H, Tunçcan OG, Oner AY, Curak MY, Senol E, et al. Brain abscess caused by Nocardia cyriacigeorgica in two patients with multiple myeloma: novel agents, new spectrum of infections. Hematology 2014;19:158-62.

8. Kim SJ, Kim K, Kim BS, Lee HJ, Kim H, Lee NR, et al. Bortezomib and the increased incidence of herpes zoster in patients with multiple myeloma. Clin Lymphoma Myeloma 2008;8:23740 .
9. Basler M, Lauer C, Beck U, Groettrup M. The proteasome inhibitor bortezomib enhances the susceptibility to viral infection. J Immunol 2009;183:6145-50.

10. Tung D, Cheung PH, Kaur P, Foreman O, Kavirayani A, Hain HS, et al. Anti-inflammatory and immunomodulatory effects of bortezomib in various in vivo models. Pharmacology 2011;88:100-13.

11. Wu KL, van Wieringen $\mathrm{W}$, Vellenga E, Zweegman S, Lokhorst HM, Sonneveld P. Analysis of the efficacy and toxicity of bortezomib for treatment of relapsed or refractory multiple myeloma in community practice. Haematologica 2005;90:9967.

12. Greipp PR, Miguel JS, Durie BGM, Crowley JJ, Barlogie B, Blad J, et al. International staging system for multiple myeloma. J Clin Oncol 2005;23:3412-20.

13. Palumbo A, Loiseau HA, Oliva S, Lokhorst HM, Goldschmidt H, Rosinol L, et al. Revised International Staging System for Multiple Myeloma: a report From International Myeloma Working Group. J Clin Oncol 2015;33:2863-9.

14. Kropff M, Bisping G, Schuck E, Liebisch P, Lang N, Hentrich $\mathrm{M}$, et al. Bortezomib in combination with intermediate-dose dexamethasone and continuous low-dose oral cyclophosphamide for relapsed multiple myeloma. Br J Haematol 2007;138:330-7.

15. Pang Y, Shao H, Yang Z, Fan L, Liu W, Shi J, et al. The neutrophils +monocyte/lymphocyte ratio is an independent prognostic factor for progression-free survival in newly diagnosed multiple myeloma patients treated with BCD regimen. Front Oncol 2020;10:1617.

16. Zeng Q, Liu Z, Li Q, Liu T. Prognostic value of neutrophil to lymphocyte ratio and clinicopathological characteristics for multiple myeloma. Medicine (Baltimore). 2018;97:e12678.

17. Suriu C, Akria L, Azoulay D, Shaoul E, Barhoum M, Braester A. Absolute lymphocyte count as prognostic marker in newly diagnosed multiple myeloma patients. Int $\mathrm{J}$ Lab Hematol 2016;38:e56-9.

18. Romano A, Parrinello NL, Consoli ML, Marchionni L, Forte $\mathrm{S}$, Conticello C, et al. Neutrophil to lymphocyte ratio (NLR) improves the risk assessment of ISS staging in newly diagnosed MM patients treated upfront with novel agents. Ann Hematol 2015;94:1875-83.

19. Wang J, Sun C, Xia J, Zhou X, Guo HF. Limited prognostic value of pretreatment neutrophil-to-lymphocyte ratios in elderly patients with multiple myeloma. Clin Lab 2018;64:507-13.

20. Romano A, Laura PN, Cerchione C, Letizia CM, Parisi M, Calafiore V, et al. The NLR and LMR ratio in newly diagnosed MM patients treated upfront with novel agents. Blood Cancer J 2017;7:649.

21. Raje N, Berdeja J, Lin Y, Siegel D, Jagannath S, Madduri D, et al. Anti-BCMA CAR T-cell therapy bb2121 in relapsed or refractory multiple myeloma. N Engl J Med 2019;380:1726-37.

22. Binder M, Rajkumar SV, Lacy MQ, Gertz MA, Buadi FK, Dispenzieri A, et al. Peripheral blood biomarkers of early immune reconstitution in newly diagnosed multiple myeloma. Am J Hematol 2019; 94:306-11.

23. Ueda T, Chikuie N, Takumida M, Furuie H, Kono T, Taruya $\mathrm{T}$, et al. Baseline neutrophil-to-lymphocyte ratio (NLR) is associated with clinical outcome in recurrent or metastatic head and 
neck cancer patients treated with nivolumab. Acta Otolaryngol 2020;140:181-7.

24. Kosuga T, Konishi T, Kubota T, Shoda K, Konishi H, Shiozaki A, et al. Clinical significance of neutrophil-to-lymphocyte ratio as a predictor of lymph node metastasis in gastric cancer. BMC Cancer 2019;19:1187.

25. Bento L, Díaz-López A, Barranco G, Martín-Moreno AM, Baile M, Martín A, et al. New prognosis score including absolute lymphocyte/monocyte ratio, red blood cell distribution width and beta-2 microglobulin in patients with diffuse large B-cell lym- phoma treated with R-CHOP: Spanish Lymphoma Group Experience (GELTAMO). Br J Haematol 2020;188:888-97.

26. Dosani T, Covut F, Beck R, Driscoll JJ, de Lima M, Malek E. Significance of the absolute lymphocyte/monocyte ratio as a prognostic immune biomarker in newly diagnosed multiple myeloma. Blood Cancer J 2017;7:e579.

27. Yang Y, Liu Z, Wang H. Peripheral absolute lymphocyte count: an economical and clinical available immune-related prognostic marker for newly diagnosed multiple myeloma. Med Sci Monit 2020;26:e923716. 